\title{
El Estado en el pensamiento de San Agustín y Santo Tomás
}

\author{
The State in the thought of Saint Augustine and Saint Thomas
}

\author{
Dr. Enrique SOMAVILLA RODRÍGUEZ* \\ enrique.somavillarodriguez@usp.ceu.es \\ Dra. Carmen CALDERÓN PATIER** \\ Universidad San Pablo-CEU \\ calder@ceu.es
}

\begin{abstract}
Resumen: San Agustín desarrolla en la obra de La Ciudad de Dios, el tema de la paz, que la define como la tranquilidad del orden, sus formas y medios para establecerla que son las leyes y el concepto de Estado. San Agustín, asume que la ciudad terrena, es decir, el poder temporal, se encuentra al servicio de la ciudad de Dios, que es el poder espiritual. Más tarde, la armonización entre la fe y la razón, que será la que sobresalga respecto a las demás posturas, por medio de santo Tomás de Aquino, OP, que intenta mantener un sano y adecuado equilibrio entre filosofía y teología. Para llegar a una sana confluencia entre ambas figuras, el primero proyecta su sistema filosófico sobre el neoplatonismo y el segundo sobre Aristóteles; de ambas corrientes, la platónica-agustiniana dejará paso a la aristotélica dominica y esta se impondrá ya en el siglo XIII de forma definitiva con el esquema tomista para el desarrollo de las tesis filosóficoteológicas. El estudio de ambos métodos proyectará una nueva cosmovisión de la realidad y del hombre.
\end{abstract}

Abstract: Saint Augustine develops in the work of The City of God, the theme of peace, which he defines as the tranquility of order, its forms and means to establish it, which are the laws and the concept of the State. Saint Augustine, assumes that the earthly city, that is, temporal power, is at the service of the city of God, which is spiritual power. Later, the harmonization between faith and reason, which will be the one that stands out compared to the other positions, through Saint Thomas Aquinas, OP, who tries to maintain a healthy and adequate balance between philosophy and theology. To reach a healthy confluence between

\footnotetext{
* Estudiante de Doctorado del Programa en Derecho y Economía de la Escuela Internacional de Doctorado, CEINDO de la USPCEU.

** Catedrática de Economía Aplicada de la USPCEU.
} 
the two figures, the first projects his philosophical system on Neoplatonism and the second on Aristotle; Of both currents, the Platonic-Augustinian will give way to the Dominican Aristotelian and this will be imposed in the 13th century in a definitive way with the Thomist scheme for the development of philosophical-theological theses. The Study of both methods will project a new worldview of reality and of man.

Palabras Clave: San Agustín, santo Tomás de Aquino, filosofía, teología, Estado, Res Publica.

Keywords: Saint Agustin, Saint Thomas of Aquino, philosophy, theology, State, Res Publica.

\section{Sumario:}

\section{Introducción.}

II. La noción de orden, Estado o Res Publica en la Ciudad de Dios.

III. Concepto de pueblo en la Ciudad de Dios.

IV. El concepto de paz recogido en la Ciudad de Dios.

V. Concepto de imperium, regnum, civitas y iustitia en la Ciudad de Dios.

VI. La irrupción de santo Tomás de Aquino, OP, en el pensamiento Medieval.

VII. Cambio en la reflexión teológica en san Agustín y santo Tomás de Aquino.

VIII. Conclusiones.

IX. Bibliografía.

Recibido: septiembre 2021. Aceptado: noviembre 2021. 


\section{INTRODUCCIÓN}

El estruendo de la caída de Roma en agosto del año 410 a manos de Alarico y el saqueo posterior sumió a san Agustín en una triste realidad. Su mundo se desmoronaba progresivamente y lo vería en su propia carne cuando antes de fallecer el 28 de agosto del 430 en Hipona fue también asediada y cercada por Genserico para caer poco más tarde. San Agustín concibe La Ciudad de Dios contra paganos, en el año 412, como la lucha entre el bien y el mal, que se orientan desde la Providencia divina. Esta Providencia lo supone todo, la existencia del bien que Dios quiere, y la presencia del mal que Dios permite para que se obtenga de él beneficios mayores. Así para san Agustín el proceso histórico es la lucha entre la ciudad terrenal, fundamentada por el egoísmo humano, y la Ciudad de Dios, dirigida por la caridad. Será Cristo el centro de la reflexión agustiniana cuando aduce que, sin Cristo la historia es ininteligible. El hombre elige libremente entre los dos sentidos. Según la opción la historia avanzará negativa o positivamente, pero siempre en orden al fin que la providencia de Dios ha previsto.

La filosofía de Agustín, tiene a su favor el haber sido capaz de sintetizar la filosofía helenística y la revelación del cristianismo. Está muy claro que, tras la desaparición del Imperio Romano de Occidente, será la Iglesia la que asuma la labor de reestructuración del pensamiento intelectual y es san Agustín la figura y la autoridad emergente, incluso cuando unos siglos más tarde, con la llegada de la Escolástica se hagan otras síntesis, que incluye a santo Tomas de Aquino. La influencia de san Agustín, aún con todo, sigue siendo permanente en el siglo XVI con la Escolástica tardía, en el Renacimiento, en el mismo Lutero, fraile agustino, en el racionalismo posterior de Descartes y Lebniz, etc. La Ciudad de Dios es una obra que posee una excepcional calidad por el plan que la inspira, por su inmenso alcance y por las perspectivas que abrió a la humanidad. Sin duda, la visión de san Agustín ha llegado hasta nuestros días con una gran profundidad. Se trata de un libro de carácter apologético que pasará a ser la primera obra de filosofia de la historia, pues recrea la historia, en el contexto de la libertad humana en la lucha entre el bien y el mal o mejor como lo plasma san Agustín como la permanente lucha entre el Reino de Dios y el reino mundano. Por eso, recalca que el Estado ahonda sus raíces en los principios profundos de la propia 
naturaleza humana, que tiene que dedicarse a las cuestiones temporales como son la paz, el bienestar, la justicia, el derecho. Además, como la potestad proviene de Dios, han de ser los valores cristianos lo que han de orientar al Estado o Res Publica. De aquí que, para san Agustín el Estado posee una significación divina.

\section{LA NOCIÓN DE ORDEN, ESTADO O RES PUBLICA EN LA CIUDAD DE DIOS}

San Agustín desarrolla en la obra de La Ciudad de Dios, el tema de la paz, que la define como la tranquilidad del orden, con sus formas y medios para establecerla que son fundamentalmente las leyes y el concepto de Estado que será una idea que reforzará a lo largo de toda la obra de la Ciudad de Dios contra paganos, en una progresión muy acertada: "Después de la ciudad, de la urbe, viene el orbe de la tierra, el llamado tercer grado de la sociedad humana: el hogar, la urbe y el orbe, en una progresión ascendente. Aquí ocurre como con las aguas: cuanto más abundantes, tanto más peligrosas. Tenemos en primer lugar la diversidad de lenguas, causa de distanciamiento de un hombre con otro hombre"1.

La paz y el orden son muy importantes en el desarrollo de la Ciudad de Dios. Define el orden como el medio más adecuado que tenemos por el cual Dios distribuye a cada persona y cada cosa en su lugar adecuado. De esta manera se puede llegar a alcanzar la paz auténtica y a través de ella la verdad y a Dios. La paz es la tranquilidad del orden, el equilibrio pleno del universo, además, de todas las partes del hombre. San Agustín distinguirá dos tipos de paz: en primer lugar, la paz terrenal humana, que nace del consenso entre los hombres y los que la gobiernan, centrada en los intereses del individuo, que nace por la necesidad humana y se basa especialmente en normas, acuerdos, pactos y alianzas. En segundo lugar, la otra paz, aquella paz celeste, la cual busca la felicidad completa, total, definitiva, que va paralela con la ética platónica que buscaba la felicidad humana, centrada en Dios. san Agustín continúa: "La familia debe ser el principio $y$ la parte mínima de la ciudad. Y como todo principio hace referencia a un fin en su género, y toda parte se refiere a la integridad del todo por ella participado, se desprende evidentemente que la paz doméstica se ordena a la paz ciudadana, es decir, que la bien ordenada armonía de quienes conviven juntos en el mandar y en el obedecer mira a la bien ordenada armonía de los ciudadanos en el mandar y obedecer. Según esto, el padre de familia debe tomar de las leyes de la ciudad aquellos preceptos que gobiernen su casa en armonía con la paz ciudadana" ${ }^{2}$. Esto le llevará a la consideración del Estado.

\footnotetext{
${ }^{1}$ SAN AGUSTÍN, De Civitate Dei, XIX, 7, PL: 41,633-634.

${ }^{2}$ SAN AGUSTÍN, De Civitate Dei, XIX, 16, PL: 41, 644-645.
} 
La tan deseada paz, aquella paz terrena también es requerida por la ciudad celeste que sigue peregrinando en la tierra, porque, aunque el hombre que pertenece a ella sigue siendo peregrino en ella, le es necesario para llevar adelante los deberes que debe asumir como cristiano. Siempre la paz celeste será mucho más perfecta porque su fin se orienta y es Dios. La paz terrena no es mala puesto que es un don de Dios. Pero aquí se entiende esa paz terrena como paz que conviene tanto a la ciudad de los hombres, es decir, terrena, como a la ciudad de Dios, celeste, en la tierra, que es la Iglesia, así deseada por ambas para llevar a cabo sus obligaciones o quehaceres. Así, la paz sólo será alcanzada en la vida eterna de modo total, pues solo allí Dios se erige como juez justo e imparcial, pero que, sin embargo, puede ser vivida en esta tierra por el ser humano en cierto modo como paz temporal ${ }^{3}$. Por eso hay que tener en cuenta que la ciudad terrestre es la que no vive de la fe, es decir, no proyecta su existencia desde el plano cristiano, desde la redención del género humano, en definitiva, desde Cristo. Eso no impide que necesite de la paz y la concordia y le convenga dicha tranquilidad de la paz y la concordia para conseguir sus fines y sus objetivos, aunque en numerosas ocasiones se viva desde el egoísmo y la vida temporal. La paz nace de la concordia entre gobernados y gobernantes, resolviendo problemas y evitando enfrentamientos.

\section{CONCEPTO DE PUEBLO EN LA CIUDAD DE DIOS}

Por otra parte, san Agustín ahonda en el término de pueblo, para definir la res publica, que admira: "Pero si la realidad "pueblo» la definimos de otra manera, por ejemplo: «Es el conjunto multitudinario de seres racionales asociados en virtud de una participación concorde en unos intereses comunes», entonces, lógicamente, para saber qué clase de pueblo es debemos mirar qué intereses tiene. No obstante, sean cualesquiera sus intereses, si se trata de un conjunto no de bestias, sino de seres racionales, y está asociado en virtud de la participación armoniosa de los bienes que le interesan, se puede llamar pueblo con todo derecho. Y se tratará de un pueblo tanto mejor cuanto su concordia sea sobre intereses más nobles, y tanto peor cuanto más bajos sean éstos. De acuerdo con esta definición, que es nuestra, el pueblo romano es verdadero pueblo, y su empresa, una empresa pública, un Estado, sin lugar a dudas. La Historia es testigo de los intereses que este pueblo tuvo en sus primeros tiempos y cuáles en etapas posteriores; de la conducta que les arrastró a rebeliones cruentas, y de aqui a las guerras sociales y civiles, rompiendo y corrompiendo esta concordia, que es -digámoslo así- la salud de un pueblo. De todo esto ya hemos hablado abundantemente en los libros precedentes. No por eso voy a negar que Roma

\footnotetext{
${ }^{3}$ Cf. SAN AGUSTÍN, De Civitate Dei, XIX, 14, PL: 41, 642-643.
} 
sea un pueblo, o que su empresa sea un Estado, con tal que se mantenga de algún modo el conjunto multitudinario de seres racionales asociados en virtud de la participación en unos intereses comunes"4.

Como hemos dicho la ciudad celeste que peregrina en la tierra, es decir la que conocemos como aquella parte de la ciudad celeste que vive en el mundo, en nuestra sociedad, en la tierra, hasta acabar su peregrinación, no es la patria celestial, la patria definitiva de Dios. Esa patria celestial es el fin de todo cristiano. Esta ciudad se diferencia de la terrestre o temporal, en que ésta tiene puesta su existencia en la fe y la esperanza de su salvación. Busca el cumplimiento de la promesa de Dios, mediante la redención del pecado y su vida se proyecta sobre la vivencia de las buenas obras. La ciudad celeste tiene necesidad de la paz terrestre y no pone en cuestión tal necesidad y procura cumplirlas y así poder llevar adelante todos los deberes y obligaciones como cristianos, seguidores del Señor, y poder realizar su peregrinación en este mundo hasta llegar a la patria del cielo, pues el cristiano no pertenece a la ciudad terrestre, aunque viva en ella, sino que como un peregrino en esta tierra que camina hacia la definitiva, patria del cielo. Pudiera parecer que la fe es la que puede dividir a los hombres, en cristianos y gentiles; en los que esperan la vida después de nuestra existencia terrena y mortal, de los que nada esperan y a veces, desesperan, envueltos en su indigencia orgullosa y soberbia. Es necesario tener en cuenta que esta paz terrestre lleva sobre sí un noble acuerdo entre cristianos y gentiles, lo que provoca un cierto orden, el cual coloca a cada persona en su lugar correspondiente, lo que dará lugar a la formación de una sociedad categorizada posteriormente. Cuando se alcance la ciudad celeste, los cristianos no necesitarán ya de la paz terrestre, puesto que disfrutará de la paz perfecta y eterna que posibilitará la felicidad del hombre y estará inmerso en la inmortalidad y la eternidad. La paz, definida magistralmente como la tranquilidad del orden ${ }^{5}$, se debe configurar cuando las sociedades se ordenan hacia el disfrute eterno de Dios, siendo la vida terrenal una preparación para ese gozo. La guerra, como mal, se presenta como una de tantas herramientas o medios destinados a conculcar el fin último de la existencia humana y social que es el logro de la paz. Si se pierde la paz, lo que se debe hacer es buscar la tranquilidad, el restablecimiento de orden alterado, siendo asumido por las personas adecuadas, príncipes, gobernantes y personas doctas.

San Agustín para poder situar ese ideal de res publica o Estado se fija en la historia de la humanidad para asentar el tema de la justicia como eje trasversal y expresa que es así cómo la concordia es esencial a la ciudad, a la res publica

\footnotetext{
${ }^{4}$ SAN AGUSTÍN, De Civitate Dei, XIX, 24, PL: 41, 655.

${ }^{5}$ SAN AGUSTÍN, De Civitate Dei, XIX, 13, 1, PL: 41, 640-641.
} 
es esencial el vínculo seguro de la paz para la seguridad de todos y del Estado ${ }^{6}$, pues, sin justicia no puede existir la concordia. De esta manera clarifica: "Pareció este tema suficientemente tratado, con lo que Escipión reanuda su interrumpido discurso. Evoca y encarece su breve definición de república: es «una empresa del pueblo», había dicho él. Y puntualiza que «pueblo» no es cualquier grupo de gente, sino «la asociación de personas basada en la aceptación de unas leyes y en la comunión de intereses». Muestra después la gran utilidad de una definición a la hora de discutir, y concluye de su definición que sólo se da un Estado («República»), es decir, una «empresa del pueblo», cuando se gobierna con rectitud y justicia, sea por un rey, sea por una oligarquía de nobles, sea por el pueblo entero. Pero cuando el rey es injusto, él lo llama «tirano», al estilo griego; cuando lo son los nobles dueños del poder, los llama "facción», y cuando es injusto el mismo pueblo, al no encontrar otro nombre usual, llama también «tirano» al pueblo. Pues bien, en este caso no se trata ya-dice él-de que la República esté depravada, como se decía en la discusión del día anterior; es que asi ya no queda absolutamente nada de República, según la necesaria conclusión de tales definiciones, al no ser una «empresa del pueblo», puesto que un tirano o una facción la han acaparado, y, por tanto, el pueblo mismo ya no es pueblo si es injusto: no sería una "asociación de personas, basada en la aceptación de unas leyes y en la comunión de intereses», según la definición de «pueblo»"

En una época de turbación, conflicto y confusión, más que nunca es necesaria la paz. Esa paz que sólo se puede conseguir como don regalado por Dios. San Agustín, siempre buscó la paz interior, inquieto deseando encontrarla. Experimentó esa falta de paz en muchos períodos de su vida. De ahí que Agustín adopta la teoría de Platón, y así reconociendo que el Estado no será realmente un buen Estado hasta que no se convierta al cristianismo. Para Agustín es el Estado el que proporcionará una buena sociedad a sus ciudadanos si se convierte al cristianismo, el cual hace a todos ciudadanos, posee un gran paralelismo con la idea de Platón, que defendía que cada uno se encuentra en un lugar por el filósofo que conoce la idea de bien y que estructura la sociedad respecto al mundo de las ideas. La Iglesia es la entidad superior al Estado, la que le proporciona aquellas ideas para hacer de él, una sociedad justa y casi perfecta. Se ve una clara semejanza con Platón, la Iglesia o príncipe cristiano como los que deben gobernar, como el filósofo en Platón, porque conocen la idea de bien, que en Agustín esta idea

\footnotetext{
${ }^{6}$ Existe una vinculación proporcional entre la concordia y la res publica y por otra de la ciudad y el Estado, respecto a la confianza como vínculo adecuado para la propia seguridad de los ciudadanos que pertenecen a la ciudad y al Estado. Cf. PACIONI, V., "Reflexiones sobre la paz en el libro XIX del De Civitate Dei de san Agustín. Suposiciones antropológicas e implicaciones políticas", en Avgvstinvs, LXV (2020) 515-546 y 528-530.

${ }^{7}$ SAN AGUSTÍN, De Civitate Dei, II, 21, 1 y 2, PL: 41, 66-67.
} 
de bien o verdad objetiva es siempre Dios, que a través de la creación ha hecho posible el universo y por medio de la providencia lo crea, gobierna y administra.

\section{EL CONCEPTO DE PAZ RECOGIDO EN LA CIUDAD DE DIOS}

San Agustín sigue con el tema de la paz porque considera el elemento esencial para el desarrollo de la ciudad o civitas, el Estado o res publica, que dará lugar a una sociedad bien pertrechada y acorde con los hombres. Ahondando, Agustín clarifica. "La paz del cuerpo es el orden armonioso de sus partes. La paz del alma irracional es la ordenada quietud de sus apetencias. La paz del alma racional es el acuerdo ordenado entre pensamiento y acción. La paz entre el alma y el cuerpo es el orden de la vida y la salud en el ser viviente. La paz del hombre mortal con Dios es la obediencia bien ordenada según la fe bajo la ley eterna. La paz entre los hombres es la concordia bien ordenada. La paz doméstica es la concordia bien ordenada en el mandar y en el obedecer de los que conviven juntos. La paz de una ciudad es la concordia bien ordenada en el gobierno y en la obediencia de sus ciudadanos. La paz de la ciudad celeste es la sociedad perfectamente ordenada y perfectamente armoniosa en el gozar de Dios y en el mutuo gozo en Dios. La paz de todas las cosas es la tranquilidad del orden. Y el orden es la distribución de los seres iguales y diversos, asignándole a

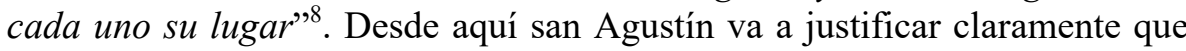
la Iglesia debe servirse de los poderes temporales, a través del orden, la paz y el bien de la res publica, para someter a los reinos terrenos al cristianismo, de la misma manera que Platón, que aseguraba mediante los guardadores la defensa de la ciudad o polis griega. De esta manera, sería el orden de la Iglesia, que como la del pensador o filósofo, conocedores del bien y de Dios, establecerá la conducta que deben seguir los ciudadanos en su vida terrena hasta que lleguen a la ciudad celeste. De esta manera la Iglesia justificó la intervención en el Estado y se defendía de la separación entre Iglesia y Estado. Así coincide con Platón, el cual afirmó que el único que tenía derecho a gobernar era el filósofo.

Durante la Edad Media, se manifiesta claramente la fuerza de la influencia que ejercía esta concepción agustiniana, de procedencia platónica y neoplatónica, especialmente con Plotino. Esto supuso un gran número de problemas, permanentes conflictos, dificultades, desavenencias entre propios y extraños, que desembocaría en persecuciones directas o encubiertas a los herejes, judíos, musulmanes que se han mantenido hasta el día de hoy de distintas formas y maneras. A san Agustín se le ha achacado cierto pesimismo, dado que su doctrina viene derivada de Platón, Plotino, los neoplatónicos, etc., pesimismo en el hombre, que en san

\footnotetext{
${ }^{8}$ San Agustín, De Civitate Dei, XIX, 13, 1, PL: 41, 640-641.
} 
Agustín va a necesitar la ayuda de Dios y en el caso de Platón, del filósofo, como aquellos que solo ellos conocen la verdad. Esto deriva fundamentalmente en la búsqueda de la felicidad por el hombre, búsqueda que en los cristianos llegaba a Dios como culmen y en Platón en acceder a la idea del Bien. En definitiva, Dios y el Bien son la misma cosa, pues Dios es el sumo Bien. Para todo ello será preciso obtener el bien de la paz. Paz entre los hombres como la concordia bien ordenada. La paz de la res publica como la concordia bien ordenada en el gobierno y en la obediencia de los ciudadanos. Aquí se encuentra como motivo central recurrente porque, la paz de todas las cosas es la tranquilidad del orden. La ciudad terrenal formada por los hombres que viven según la carne y que anteponen el amor egoísta al amor de Dios. La ciudad de Dios, formada por los hombres que viven según el espíritu, que son los que aman a Dios. Basada en la caridad y modelo de la sociedad, donde brillan la justicia, el orden y la paz auténtica. Ambas ciudades conviven en el seno de las sociedades históricas. Anteponen opciones diametralmente opuestas la ciudad de Dios y la ciudad de los hombres. Una orientada por el egoísmo y la obra llevada por la caridad. El pensamiento agustiniano lleva implícito la búsqueda? .

Agustín había dejado planteado el tema, si Roma fuera Estado. Su justicia no es justicia autentica, Roma no era una verdadera república ${ }^{10}$. Apela a Cicerón, apoyándose en sus mismas definiciones donde clarifica el concepto de pueblo y Estado. Roma ya no representaba ni los valores ni las grandes empresas que se propuso en el pasado. "Esto confesaba Cicerón mucho después, es verdad, de la muerte de "el Africano», haciéndole discutir sobre el Estado en su obra, pero ciertamente antes de la venida de Cristo. Si estos pareceres hubieran sido expresados después de la difusión y victoria del cristianismo, ¿qué pagano dejaría de imputar tal decadencia a los cristianos? ¿Y por qué entonces los dioses no se preocuparon de que no pereciese y se perdiera aquella República que Cicerón, mucho antes de la venida de Cristo en carne mortal, con acentos tan lúgubres deplora haber sucumbido? Miren a ver los admiradores que ella tiene cómo fue incluso en la época de antiguos héroes $y$ viejas costumbres, a ver si estaba vigente la auténtica justicia, o tal vez ni siquiera entonces estuviera viva por sus costumbres, sino apenas pintada de colores, cosa que el mismo Cicerón, sin pretenderlo, expresó al exaltarla. Pero esto, si Dios quiere, lo trataremos en otro lugar. Me esforzaré en su momento por demostrar que aquel no fue nunca Estado auténtico (república), porque en él nunca hubo auténtica justicia. Y esto lo haré apoyándome en las definiciones del mismo Cicerón, según las cuales él brevemente, por boca de Escipión,

\footnotetext{
${ }^{9}$ Ante todo, búsqueda de la verdad, buscando la verdad llega a descubrir a Dios.

${ }^{10}$ Roma había perdido toda su importancia cuando había dejado de ser justa, su justicia no era auténtica.
} 
dejó sentado qué es el Estado y qué es el pueblo (apoyándolo también en otras muchas afirmaciones suyas y de los demás interlocutores de la discusión). En rigor, si seguimos las definiciones más autorizadas, fue, a su manera, una república, y mejor gobernada por los viejos romanos que por los más recientes. La verdadera justicia no existe más que en aquella república cuyo fundador y gobernador es Cristo, si es que a tal Patria nos parece bien llamarla así, república, puesto que nadie podrá decir que no es una «empresa del pueblo». $Y$ si este término, divulgado en otros lugares con una acepción distinta, resulta quizá inadecuado a nuestra forma usual de expresarnos, sí es cierto que hay una auténtica justicia en aquella ciudad de quien dicen los Sagrados Libros: ¿Qué pregón tan glorioso para ti, Ciudad de Dios!" 11.

Para Platón existe un derecho fundamental que es la justicia como la base de la vida política. San Agustín le dará una nueva dimensión a esta justicia, considerando el culto a Dios verdadero como la justicia verdadera, que debe informar el espíritu de toda la sociedad política. Si falló en imperios y reinos anteriores fue porque sus acciones carecían de la debida ordenación al verdadero fin, que es el Bien supremo que era Dios. Esto no quiere decir que no existiese la justicia en ellos, pues muchos tenían leyes justas promulgadas para el bienestar de la res publica. Faltaba en ellos su orientación esencial que da el conocimiento del verdadero Dios. Faltaba en todos ellos la rectitud en sus virtudes que eran torpes, defectuosas e imperfectas.

Para Agustín parece claro que la ausencia de esa justicia y esa res publica que Roma ya no representaba, ni tampoco conformaban el verdadero y auténtico ideal pues había sucumbido ante los empujes de los bárbaros que hicieron caer progresivamente el Imperio. Así todos los hombres viven en sociedad y se puede suponer que esa vida social va penetrando sistemáticamente en todos los aspectos de la misma y de la vida humana, siendo el ideal, la sumisión de la vida política a las exigencias morales del Evangelio y la ley natural.

\section{CONCEPTO DE IMPERIUM, REGNUM, CIVITAS Y IUSTITIA EN LA CIUDAD DE DIOS}

San Agustín echará mano a los temas de la res publica, la justicia y el derecho. Serán temas que influyen poderosamente en el siglo XVI con los tratados de Iustitia et Iure ${ }^{12}$. "A saber: que en las definiciones formuladas

\footnotetext{
${ }^{11}$ SAN AGUSTÍN, De Civitate Dei, II, 21, 4, PL 41, 68-69.

${ }^{12}$ Cf. PEDRO DE ARAGÓN, In secundam secundae Divi Thomae Angelici Commentaria. De Iustitia et Iure, Salmanticae 1590.
} 
por Escipión en la obra ciceroniana titulada La República, jamás ha existido un Estado romano. Define él con brevedad el Estado (res publica) como una «empresa del pueblo». Si esta definición es verdadera, nunca ha existido un Estado romano, porque nunca ha sido empresa del pueblo, definición que él eligió para el Estado. Define el pueblo, efectivamente, como una multitud reunida en sociedad por la adopción en común acuerdo de un Derecho y por la comunión de intereses. Qué entiende él por adopción de un Derecho lo va explicando a través de la discusión, y demuestra así cómo no puede gobernarse un Estado sin justicia. Porque donde no hay justicia no puede haber tampoco un Derecho. Lo que se hace según Derecho se hace con justicia. Pero lo que se hace injustamente es imposible que sea según Derecho. Y no podemos llamar Derecho ni tenerlo como tal a las injustas determinaciones de los hombres, siendo así que estos mismos hombres sostienen que el Derecho dimana de la fuente de la justicia, y desmienten como espuria la afirmación que suelen repetir algunos espiritus torcidos, que es Derecho lo que reporta utilidad al más fuerte. Así que donde no hay verdadera justicia no puede haber una multitud reunida en sociedad por el acuerdo sobre un Derecho, es decir, no puede haber un pueblo, según la citada definición de Escipión, o, si preferimos, de Cicerón. Y si no hay pueblo, tampoco habrá empresa del pueblo, sino una multitud cualquiera que no merece el nombre de pueblo. Ahora bien, si el Estado (res publica) es la empresa del pueblo, y no hay pueblo que no esté asociado en aceptación de un Derecho, y tampoco hay Derecho donde no existe justicia alguna, la conclusión inevitable es que donde no hay justicia no hay Estado. La justicia, por otra parte, es la virtud que da a cada uno lo suyo. Ahora bien, ¿qué justicia humana es aquella que arranca al hombre del Dios verdadero para hacerlo esclavo de los impuros demonios? ¿Es esto darle a cada uno lo suyo? ¿O es que robarle la hacienda a quien la habia comprado, dándosela a otro que no tenía ningún derecho sobre ella, lo llamaremos injusto, y si uno se sustrae a si mismo de la autoridad de Dios, que lo ha creado, y se hace esclavo de los malignos, a esto lo llamaremos justo?"13. Aún más, la ciudad, la comunidad política, el Estado ${ }^{14}$, se sitúa por encima de los individuos. El orden de propio universo, su justicia, llevará a la necesidad del Estado. Al hablar de lo colectivo, de alguna manera ello queda impregnado de una estructura política, con una llamada a la estabilidad. La comunidad política ha de estar sometida y regida por la justicia, que desde el orden político se explícita en el estado de justicia total. Si hablamos de estado, no posee las mismas atribuciones de hoy, sostenidas, tal cual, sino como un equivalente a una sociedad politicamente organizada, de manera independiente de cuál sea la estructura política concreta. Se puede

${ }^{13}$ SAN AGUSTIN, De Civitate Dei, XIX, 21, 1, PL: 41, 648-649.

${ }^{14}$ Cf. PACIONI, V., "Reflexiones sobre la paz en el libro XIX del De Civitate Dei de san Agustín. Suposiciones antropológicas e implicaciones políticas", en Avgvstinvs, LXV (2020) $515-546$ y $535-544$. 
afirmar que las entidades políticas antiguas, imperios, reinos, no eran de todo Estados si los comparamos con los actuales, aplicando criterios y conceptos de nuestra contemporaneidad.

De nuevo san Agustín tomará la escritura y expondrá una respuesta determinante para comprender mejor lo dicho sobre justicia, pueblo y res publica, Así responde: "En conclusión, pues: cuando falta la justicia de que hemos hablado, en virtud de la cual el único y supremo Dios, según la ley de su gracia, da órdenes a la ciudad que le obedece de no ofrecer sacrificios más que a Él solo, y como consecuencia que en todos los hombres, miembros de esta ciudad y obedientes a Dios, el alma sea fiel dueña del cuerpo, y la razón de los vicios, según un orden legítimo; y que lo mismo que un solo justo, asi también una comunidad y un pueblo de justos vivan de la fe, fe que se pone en práctica por el amor, un amor por el que el hombre ama a Dios, como debe ser amado, y al prójimo como a sí mismo; cuando, pues, falta esta justicia no hay una comunidad de hombres asociados por la adopción en común acuerdo de un derecho y una comunión de intereses. Si esto falta -dando como verdadera la anterior definición de pueblo-, ciertamente no existe un pueblo. Y, por tanto, ni tampoco Estado (res publica), ya que no hay empresa común del pueblo donde no hay pueblo"15.

Y lo remata aduciendo claramente su posición. Trata de determinar la cuestión:

"Pero si la realidad «pueblo» la definimos de otra manera, por ejemplo: «Es el conjunto multitudinario de seres racionales asociados en virtud de una participación concorde en unos intereses comunes», entonces, lógicamente, para saber qué clase de pueblo es debemos mirar qué intereses tiene. No obstante, sean cualesquiera sus intereses, si se trata de un conjunto no de bestias, sino de seres racionales, y está asociado en virtud de la participación armoniosa de los bienes que le interesan, se puede llamar pueblo con todo derecho. $Y$ se tratará de un pueblo tanto mejor cuanto su concordia sea sobre intereses más nobles, y tanto peor cuanto más bajos sean éstos. De acuerdo con esta definición, que es nuestra, el pueblo romano es verdadero pueblo, y su empresa, una empresa pública, un Estado, sin lugar a duda ${ }^{16}$. Es preciso recordar que desde san Agustín el estudio de la filosofía queda supeditada a la teología. Todo el pensamiento quedaba sujeto al principio de autoridad. Se discierne con claridad el carácter legítimo de las instituciones políticas, aunque eso no signifique que se orienten desde los postulados fe y la gracia, sino más bien desde la naturaleza

\footnotetext{
${ }^{15}$ SAN AGUSTÍN, De Civitate Dei, XIX, 23, 5, PL: 41, 655.

${ }^{16}$ SAN AGUSTÍN, De Civitate Dei, XIX, 24, PL: 41, 655-656.
} 
y la razón ${ }^{17}$. A partir de aspectos, ya recogidos por san Agustín en De Civitate Dei II, 21, 4 y XIX, 21,1, y que son de máxima importancia para establecer claramente el concepto de civitas populus y res publica, se puede afirmar la conexión interna con las tres realidades u órdenes sociopolíticos con el tema de la iustitia. Casi siempre san Agustín usa el término de res publica, el significado estrictamente político de civitas romana, aunque no siempre. El populus es el sujeto o contenido humano de la civitas, a través del cual, y sobre el cual actúa ésta, mientras que la res publica, es el fondo de las cosas y asuntos que dan volumen y objeto a la acción. San Agustín maneja de manera sinónima los conceptos y los términos de res publica y civitas, de igual manera en la tensión entre la romanitas y la cristianitas. Esto supone un frente de orden dialéctico de ambas civitates, se torna en beligerancia activa entre las dos: res publicae, una terrenal y la otra celestia $1^{18}$. Todas se hallan vinculadas en La Ciudad de Dios ${ }^{19}$. Para san Agustín la palabra imperium es fundamental en la concepción romana del derecho y el Estado. Proviene del verbo imperare, unido al sustantivo imperator, que es investido de poder para dirigir y gobernar la res publica. Para san Agustín hay una relación dominativa y peculiar imperium vel dominationem, con un nexo de auctoritas y publica potestas, que se desenvuelve en función soberana de mando sobre el territorio de la civitas, grande en proporciones e integrado por diversidad de pueblos ${ }^{20}$. Otra dimensión recogida es la del término regnum. Proviene del término regnare, que conlleva la relación íntima con rex o princeps. Regnum a regibus y reges a regendo, son el itinerario intelectual de san Agustín ${ }^{21}$. El hombre es miembro, de igual modo de la civitas y del regnum, según el pensamiento agustiniano ${ }^{22}$. Además, al decir civitas Dei, viene a expresarnos el regnum Christi, porque Cristo es su fundador y su rey ${ }^{23}$. Por eso la civitas Dei, en su peregrinación sobre la tierra es también peregrina civitas regis Christi $^{24}$. Dicha peregrinación temporal permanece en sus ciudadanos hasta el final de los tiempos hasta que llegue el reino definitivo.

${ }^{17}$ La filosofía se convirtió en auxiliar de la teología, intentará dar respuestas a la relación entre fe y razón, la causalidad y los límites del conocimiento, entre libertad y omnisciencia de Dios. Cf. OCÁRIZ, F., y BLANCO, A., Revelación, Fe y Credibilidad. Curso de teología fundamental, Madrid 1998, p. 15.

${ }^{18}$ Cf. ESTAL, G. del, y ROSADO, J.J., "Equivalencia de Civitas en el De Civitate Dei", en La Ciudad de Dios, CLXVII, Estudios sobre la Ciudad de Dios, II, El Escorial 1954, pp. 367-454: especialmente 400-402.

${ }^{19}$ Cf. SAN AGUSTIN, De Civitate Dei, XIX, 21, 1, PL: 41, 648-649.

${ }^{20}$ SAN AGUSTIN, De Civitate Dei, V, 19, PL: 41,165.

${ }^{21}$ SAN AGUSTÍN, De Civitate Dei, V, 12, 1, PL: 41,154.

${ }^{22}$ SAN AGUSTÍN, De Civitate Dei, IV, 3, PL: 41,114.

${ }^{23}$ SAN AGUSTÍN, De Civitate Dei, XV, 8,1, PL: 41,446.

${ }^{24}$ SAN AGUSTÍN, De Civitate Dei, I, 35, PL: 41,46. 
El reino definitivo ${ }^{25}$ de Cristo, sin fin y para siempre ${ }^{26}$. Por tanto, regnum y civitas se corresponden en san Agustín ${ }^{27}$. Todos los peregrinos, conducidos por Cristo, caminan por la paz de la patria celeste ${ }^{28}$, hasta que puedan llegar al reino eterno de la ciudad santa ${ }^{29}$. Así todos los miembros de esa patria reinarán por siempre con Cristo en la paz definitiva y gozosa de dicha ciudad ${ }^{30}$. No es del todo fácil poder encontrar en español el término adecuado y con la fuerza suficiente para expresar con mayor riqueza, lógica y la fuerza de la política del vocablo civitas, pues suele suceder que en latín posee mayor profundidad y sentido que en español ${ }^{31}$, en la mayoría de las ocasiones. Para san Agustín su obra la Ciudad de Dios, asume que la ciudad terrena, es decir el poder temporal, se encuentra al servicio de la ciudad de Dios, que es el poder espiritual.

Con el tiempo el papado va perdiendo cuotas de poder, por considerar fundamental la concentración absoluta del poder, tanto temporal como espiritual en una sola persona. De aquí florecerá en el último cuarto del siglo XI, la figura del Gregorio VII, con su afán reformador escribe la famosa bula Dictatus Papae ${ }^{32}$, elenco con veintisiete proposiciones que precisaba el primado del Santo Padre, en la que se posiciona dando mayor capacidad de poder, no sólo ya en la Iglesia sino también sobre el poder temporal de los emperadores y poder eximir a los súbditos de su lealtad a los monarcas. A pesar de las dificultades que van abriéndose paso en los siglos sucesivos entre la nueva sociedad que se avecina, los pontífices siguen con la máxima fuerza. La subordinación del poder terrenal o secular al poder divino o espiritual, pues este tiene la potestad de encauzar y orientar a aquel. Todo queda al juicio de Dios. Con posterioridad a la muerte de santo Tomás de Aquino (1225-1274), Bonifacio VIII en su bula Unam Sanctam ${ }^{33}$, se propone defender firmemente y con toda la fuerza, el sometimiento de todo el poder temporal al poder espiritual. De ahí que la soberanía o el ejercicio del poder temporal del Estado, se ha de ejercer desde las leyes positivas, y no tiene

${ }^{25}$ Cf. ESTAL, G. del, y ROSADO, J.J., "Equivalencia de Civitas en el De Civitate Dei", en La Ciudad de Dios, CLXVII, Estudios sobre la Ciudad de Dios, II, El Escorial 1954, pp. 367-454: especialmente 415-418.

${ }^{26}$ SAN AGUSTÍN, De Civitate Dei, XV, 1,2, PL: 41,438.

${ }^{27}$ SAN AGUSTÍN, De Civitate Dei, IV, 4, PL: 41,115.

${ }^{28}$ SAN AGUSTÍN, De Civitate Dei, XV, 6, PL: 41,442.

${ }^{29}$ SAN AGUSTÍN, Confesiones, XI, 2, 3, PL: 32,810.

${ }^{30}$ SAN AGUSTÍN, De Civitate Dei, V, 17,2, PL: 41, 161.

${ }^{31}$ Cf. ESTAL, G. del, y ROSADO, J.J., "Equivalencia de Civitas en el De Civitate Dei", en La Ciudad de Dios CLXVII, Estudios sobre la Ciudad de Dios, II, El Escorial 1954, pp. 367-454: especialmente 450-454.

${ }^{32}$ Cf. GREGORIO VII, Bula Dictatus Papae 1075, en Registrum PL: 148, 407-408.

${ }^{33}$ Cf. BONIFACIO VIII, Bula Unam Sanctam 1302, en Enchiridion symbolorum, definitionum et declarationum de rebus fidei et morum o El magisterio de la Iglesia. Manual de los símbolos, definiciones y declaraciones de la Iglesia en materia de fe y costumbres, Barcelona 2017, DH 870-875, pp. 379-381. 
carácter absoluto, dado que queda supeditado por la ley natural. La autoridad viene dada por Dios al pueblo, y éste es el que la delega en el gobernante, postura recogida mucho más tarde por fray Luis de León, OESA, pero que no está claro en santo Tomás de Aquino, OP. A pesar de esa falta de claridad, santo Tomás asume que el que gobierna siempre habla como representante del pueblo, mantiene dicha facultad mientras lo representa y para el bien de ese pueblo.

\section{LA IRRUPCIÓN DE SANTO TOMÁS DE AQUINO, OP, EN EL PENSAMIENTO MEDIEVAL}

Podemos definir el agustinismo político como la corriente de pensamiento que, apoyado en las ideas de san Agustín, intenta dar una respuesta a la cuestión de las relaciones entre la Iglesia y el poder temporal, donde identifica la ciudad terrena con el Imperio Romano y la ciudad celeste con la Iglesia ${ }^{34}$. Hay que comprender que hasta el siglo XIII, las figuras de la escolástica siguen una línea neoplatónica agustiniana, pues san Agustín había ejercido su influencia durante la alta Edad Media. Pero el descubrimiento de Aristóteles, traducida su obra, la escolástica imprime un giro en la evolución del pensamiento filosófico. Las discusiones entre fe y razón van a suponer un gran conflicto, en torno al cual, se van a desarrollar las mayores dificultades a la hora de encajar la fe católica. Se postulan tres alternativas posibles: en primer lugar, lo que maximizan la fe y relegan a la razón; en segundo lugar, lo que alegan sólo la razón y, por último, en tercer lugar, los que la tienen en consideración a ambas. Esta postura buscará una armonización entre la fe y la razón, que será la que sobresalga respecto a las demás, por medio de santo Tomás de Aquino, $\mathrm{OP}$, intentando mantener un sano y adecuado equilibrio entre filosofía y teología. Ante esta situación, el esplendor de la escolástica se encuentra en el trabajo desarrollado por la Escuela de traductores de Toledo, que ayudó a conocer las obras de los clásicos como Aristóteles, mediante las traducciones al árabe y al latín. A pesar de las grandes dificultades y el rechazo inicial, consiguieron al final integrarse en el pensamiento filosófico del momento.

Hay que tener en cuenta que las corrientes del pensamiento vienen representadas por san Agustín y santo Tomás de Aquino; el primero proyecta su sistema filosófico sobre el neoplatonismo y el segundo sobre Aristóteles; de ambas corrientes, la platónica-agustiniana dejará paso a la aristotélica dominica y esta se impondrá ya en el siglo XIII de forma definitiva con el esquema tomista para el desarrollo de las tesis filosófico-teológicas, y de esta manera se conformará

${ }^{34}$ Cf. ARQUILLIÈRE, H. X., El agustinismo político. Ensayo sobre la formación de las teorías políticas de la Edad Media, Granada 2005. 
el universo del pensamiento de la baja Edad Media, asumiendo la Iglesia dicha opción para el desarrollo de su quehacer teológico y en conformidad con lo definido en los concilios. Sin duda, otro aspecto que es necesario considerar en este contexto, dentro de la escolástica, fueron las relaciones entre el Imperio y la Iglesia. El poder temporal y el poder espiritual debatían su omnipresencia en la vida de la sociedad. Las relaciones entre ambos estamentos, era esencial para el buen funcionamiento entre la acción del Estado y la de la Iglesia. ¿Quién era superior la Iglesia o el Estado? Ambos conformaron la misma existencia de la vida social y política durante la Edad Media ${ }^{35}$. Era preciso delimitar las competencias entre ambas entidades. Para unos el poder civil era diferente e independiente del poder eclesial; para otros se mantenía la proposición por la que la Iglesia poseía la autoridad sobre el poder civil. Este fue un conflicto permanente a lo largo del tiempo, sin visos de solución. Prevalecía el poder espiritual sobre el temporal o más bien lo contrario. O ambos eran totalmente independientes con sus esferas de influencia propias. Tales discrepancias entre ambas esferas ayudarían poco en el futuro.

San Agustín había mantenido que la sociedad era necesaria para el hombre, partiendo de la base en la defensa de la Iglesia sobre el poder político, y planteaba la sumisión de éste a aquélla. Era una dependencia clara y determinante. La sociedad, según san Agustín, no será perfecta, el tema de la familia, sus instituciones, provenían de la misma naturaleza humana y el poder procedía directamente de Dios. San Agustín, siguiendo la línea de su pensamiento neoplatónico, idealista y místico, establecía el orden del poder de la Iglesia. Esta corriente filosófica mantuvo los objetivos del pensamiento humano hasta el siglo $\mathrm{XI}^{36}$, ejerciendo su gran influencia, pero a partir de ese momento, en el siglo XII, sería el aristotelismo el que copó su esfera de influencia con santo Tomás de Aquino, $\mathrm{OP}^{37}$. Su expresión sobre la política y la filosofía jurídica, se basa en la idea de la justicia legal, de Aristóteles y del concepto del orden de san Agustín. Su aportación a la visión de la política será la ley como la disposición de la razón para el bien común, que ha sido promulgada por quien tiene el cuidado de la comunidad ${ }^{38}$. La difusión realizada por las mismas, unidas a las grandes Órdenes Mendicantes que aparecen en el medievo como eran los dominicos, franciscanos, agustinos y carmelitas tuvieron un papel muy importante en su labor de difusión. Las universidades, pondrán su acento en el papel de la filosofía y la teología, como el eje central de los estudios universitarios y los mendicantes las asumirán como nueva orientación de su labor evangelizadora y dar mayor sentido a la nueva obra de la misión. En

\footnotetext{
${ }^{35}$ Cf. GILSON, E., El espiritu de la filosofia medieval, Madrid 2004.

${ }^{36}$ Cf. ROMERO, J.L., La Edad Media, Madrid 2001.

${ }^{37}$ Cf. FORMENT, E., Santo Tomás: su vida, su obra y su época, Madrid 2009.

${ }^{38}$ Cf. SANTO TOMÁS DE AQUINO, Summa Theologica, I-II, q. 90, art.4.
} 
vanguardia de las discusiones escolásticas irán esos mismos dominicos, franciscanos, agustinos y posteriormente jesuitas. Ante la llegada de los nuevos tiempos, la Baja Edad Media, se asume una distinta y nueva realidad secular con grandes transformaciones de tipo político, social económico y cultural muy fuertes, con una estructuración monárquica, además de la gran influencia de las Órdenes Mendicantes, dedicadas en gran medida a la labor misionera centrada en las ciudades, disciplinada e intelectual, frente a las grandes Órdenes Monásticas que se desarrollaron en el campo y la ruralidad, con una vida de clausura, piedad y de gran recogimiento, fruto de la época en la que se desarrollaron. Todo este proceso llevará a la sociedad a una modernización económica y a una mayor capacidad social que supondrá preparar los cambios para una sociedad renacentista. Tomás seguirá los pasos a Agustín.

\section{CAMBIO EN LA REFLEXIÓN TEOLÓGICA EN SAN AGUSTÍN Y SANTO TOMÁS DE AQUINO}

Avanzada ya la Edad Media, va decayendo progresivamente las posturas agustinianas, incluso dentro del pensamiento eclesial. Influyen poderosamente las ideas emergentes de san Alberto Magno y santo Tomas de Aquino, que a diferencia con san Agustín son más bien de corte aristotélico, mientras que la de Agustín caminan especialmente por los derroteros de Platón y sobre todo de Plotino. El siglo XIII va a ser determinante para este nuevo despertar filosóficoteológico. En este despertar influyen dos filósofos cordobeses de gran prestigio como son Averroes y Maimónides ${ }^{39}$. El primero comenta a Aristóteles y será una fuerte referencia para los seguidores del gran filósofo clásico y de santo Tomás. De otro lado, el judío sefardí Maimónides, estudioso de la Torá, en su Guía de los perplejos, donde asienta las creencias judías sobre bases aristotélicas y tratará de armonizar la relación entre fe y razón, acordes con las de Tomás de Aquino $^{40}$. La vinculación existente entre el cristianismo y la filosofía viene desarrollada, desde sus inicios, por el predominio de la fe sobre la razón. Esta postura queda bien reflejada en el Credo ut intelligam de san Agustín, tributario del Credo quia absurdum est de Tertuliano ${ }^{41}$, y que se apoyará a lo largo de toda la tradición filosófica hasta santo Tomás de Aquino, quien establecerá una nueva relación entre fe y razón, otorgándola una mayor autonomía. Por

${ }^{39}$ Cf. BEUCHOT, M., Introducción a la filosofía de Santo Tomás de Aquino, México 2000, p. 19.

${ }^{40}$ Cf. GARCÍA LÓPEZ, J., Tomás de Aquino, razón y fe, Madrid 1994; GILSON, E., Introducción a la Filosofía de Santo Tomás de Aquino, Pamplona (Navarra) 2009.

${ }^{41}$ Cf. TERTULIANO, "De Carne Christi V, 4", en Oehler, F., Tertulliani opera omnia, Vol. II, 5, Leipzig 1851-1854. También TERTULIANO, "De Carne Christi V, 4", en MAHE, J.-P., (ED.), La chair du Christ, T.I Sources Chrétiennes, Paris 1975. 
eso, Tomás de Aquino, siendo deudor de la tradición de la filosofía cristiana, que es eminentemente agustiniana, pone de manifiesto la preponderancia de la teología sobre la filosofía, incluidos los elementos de la fe que son imprescindibles para la reflexión tanto filosófica como teológica: verdades reveladas en la Sagrada Escritura, la creación, la inmortalidad, la concepción lineal de la historia, en contra del pensamiento clásico que la suponía cíclica. La dependencia de la filosofía y la razón en función de la fe, santo Tomás, la cambia substancialmente.

Durante esa época, el siglo XIII, se había abierto paso la teoría de la doble verdad, según la cual, existiría una verdad para la filosofía y otra para la teología, que eran independientes, cada cual con su ámbito de conocimiento y de aplicación. Así la verdad de la razón podría coincidir con la verdad de la fe o no. No podían inmiscuirse la una en la otra. Santo Tomás aportará la idea de una sola verdad, que puede ser conocida por ambas: fe y razón ${ }^{42}$. El planteamiento ya tradicional exponía que la filosofía debía estudiar el conocimiento de las verdades naturales, que son tratadas a la luz natural de la razón; mientras la teología trataría del conocimiento de la verdad revelada, verdad que sólo puede ser conocida mediante la luz de la revelación de Dios. Ello suponía una modificación fundamental de la concepción tradicional de corte agustiniano sobre las relaciones entre la razón y la $\mathrm{fe}^{43}$. La filosofía, en el ámbito propio de su aplicación que es la razón, de alguna manera, ya no era la servidora de la teología, pues se le reconocía un objeto y un método propio para el conocimiento ${ }^{44}$. Sin embargo, santo Tomás aceptará la existencia de un terreno propio a la filosofía y a la teología, que estarían representados por los llamados preámbulos de la fe $\mathrm{f}^{45}$. En este aspecto, la filosofía seguirá siendo una auxiliar útil a la teología y, para Tomás de Aquino la seguirá denominado servidora de la teología.

Con el correr de los siglos, la separación entre filosofía y teología será una de las evidencias de la modernidad. Como san Agustín, santo Tomás de Aquino, OP, tendrá una profunda preocupación por la dimensión social del hombre: por la justicia, el derecho, el bien común, por las formas de gobierno que pueden influir en su desarrollo. Santo Tomás sigue especialmente a Aristóteles. Realiza un gran esfuerzo intelectual para compatibilizar y equilibrar su pensamiento con la concepción espiritual y creyente de la existencia humana. Es preciso dar una verdadera respuesta al tema de las relaciones entre la Iglesia y el poder de las monarquías que se quieren distanciar de la nobleza. Establecer cuáles

${ }^{42}$ Cf. Cf. BEUCHOT, M., Introducción a la filosofía de Santo Tomás de Aquino, México 2000, pp. 19-20.

${ }^{43}$ Cf. GARCÍA LÓPEZ, J., Tomás de Aquino, razón y fe, Madrid 1994.

${ }^{44}$ Cf. FERRARA, R., "El ministerio sapiencial de la filosofía y la teología especulativa", en Teología 31(1978) 5-24.

${ }^{45}$ Cf. ORTÚZAR, M., "La filosofía de los preámbulos de la fe”, en Estudios, 72 (1966) 3-22. 
son sus funciones específicas para cada una de ellas; mantener la primacía de la Iglesia sobre los temas que son privativos de la misma como el fin sobrenatural del hombre; la organización de la res publica, con respecto al destino definitivo del hombre, que va más allá de lo meramente terreno, que es Dios. Santo Tomás escribirá una obra llamada la monarquía. En ella habla, siguiendo a Aristóteles, que el rey debe actuar de manera racional, debiendo conseguir siempre el bien común y la justicia ${ }^{46}$. También defenderá que mientras Dios es el gobernante del mundo, el rey ha de ser el organizador del Estado, haciendo un gran paralelismo entre ambos poderes, uno subordinado al otro. Igualmente, afirmará la dimensión social de lo humano. Sólo viviendo en sociedad, el hombre podrá alcanzar todo el desarrollo de sus capacidades y la satisfacción de sus necesidades. Por eso el fin de la sociedad y del Estado es garantizar la justicia, el bien común, la armonía social. El poder del rey no puede estar sujeto a sus veleidades o abusos, sus caprichos o excentricidades, sus gustos o arbitrariedades, nunca. Estar en posesión o en el pleno ejercicio del poder no justifica sus malos comportamientos, tampoco.

Santo Tomás sigue a Aristóteles, respecto a las formas de gobierno, pero aduce que la más completa es la monarquía, porque es la única que puede garantizar el orden interno de la sociedad y, además, porque se muestra como el ideal que Dios tiene sobre el mundo creado. La res publica, el Estado, la administración pública recoge como aspectos de su competencia la organización del hombre sobre los aspectos y la dimensión social, acerca de los dominios propios de la vida de la sociedad y del mundo, mientras que respecto a los que se refieren al bien espiritual y religioso, el bien supremo, le corresponde a Dios y a sus vicarios en la tierra. Por eso, la importancia que da al papa y a la Iglesia. Así aclara que son independientes la Iglesia y el Estado: pero existe una subordinación manifiesta de lo material a lo espiritual, lo humano a lo divino, lo natural a lo sobrenatural, de la Iglesia sobre el Estado, en los aspectos que son comunes.

Para santo Tomás, los medios o instrumentos necesarios para que el Estado cumpla sus funciones debidas, han de pasar siempre por el bien común, el derecho, las leyes, que han de ser establecidas siempre por la autoridad competente y asumidas por la sociedad, por los hombres. Para ser auténticas han de estar de acuerdo con la ley natural racional. Para santo Tomás, se puede apreciar el esquema de identificación con la verdad y de la suma complementariedad, que es el mayor empuje y la gran influencia que ha orientado todo el pensamiento cristiano después de san Agustín. Por tanto, la base del modelo teológico tomista, se encuentra en el vínculo que se produce entre la dimensión racional, de orden filosófico y la reflexión transcendente, de orden teológico. Sin duda,

\footnotetext{
${ }^{46}$ Cf. SANTO TOMÁS DE AQUINO, La monarquía, Barcelona 2007.
} 
es la mayor aportación de su propuesta teológica, se encuentra en la Summa theologica, para los cristianos, incluso la Suma contra Gentiles, de índole filosófica y religiosa, para otros creyentes que, aceptando al mismo Dios, aunque no acepten la revelación de Jesucristo, como judíos y musulmanes ${ }^{47}$. Por eso, como decía Pablo VI, con ocasión del séptimo centenario de su muerte, sobre la importancia de su sistema filosófico-teológico: "Mientras Aristóteles y otros filósofos -con las debidas rectificaciones y adaptaciones- podían y pueden aceptarse en virtud del valor universal de sus principios, su respeto a la realidad objetiva y su reconocimiento de un Dios distinto del mundo, no puede decirse lo mismo de las filosofías o teorías científicas, cuyos principios fundamentales sean incompatibles con la fe religiosa, ya por apoyarse en el monismo, ya por negar la trascendencia, ya por su subjetivismo o su agnosticismo. Desgraciadamente hay muchas doctrinas y sistemas modernos radicalmente irreconciliables con la fe y la teología cristianas. Sin embargo, santo Tomás enseña cómo, incluso en este caso, dichos sistemas pueden proporcionar, ya aportaciones particulares útiles para el perfeccionamiento y desarrollo constantes de la doctrina tradicional, ya al menos estímulos para reflexionar sobre puntos antes ignorados o insuficientemente explicados" ${ }^{\text {48 }}$. Tomás de Aquino ayuda no sólo en la filosofía y en la teología, con su método ${ }^{49}$, sino también, en el orden social, político ${ }^{50}$ y del derecho.

\section{CONCLUSIONES}

La ciencia de la fe por ser una participación de la verdad infalible de Dios, supone con respecto a nuestra ciencia racional, el juicio de la "suprema regula veritatis" que nunca puede estar en contradicción con nuestro conocimiento racional. Santo Tomás tiene como planteamiento, la firme resolución de buscar un itinerario o camino para el hombre.

Este ha sido creado a imagen y semejanza de Dios, llegue a alcanzar el bien supremo y conseguir el fin último. Su método teológico se fundamenta en una férrea y sólida base lógica y metafísica, y desarrolla la ciencia de la fe. Busca desde el humilde reconocimiento del orden que las cosas poseen en

${ }^{47}$ Santo Tomás es uno de los mayores influyentes de la teología y en la civilización del Occidente. Sin duda, su pensamiento se ha denominado Filosofía perenne. Logró sintetizar las grandes corrientes del quehacer y pensamiento filosófico y teológico, además, de una cosmovisión cristiana integrada.

${ }^{48}$ Cf. PABLO VI, "Carta Lumen Ecclesiae en el VII centenario de la muerte de santo Tomás de Aquino” 18, en AAS, 66 (1974) 673-702: especialmente 691-692.

49 Cf. PABLO VI, "Carta Lumen Ecclesiae en el VII centenario de la muerte de santo Tomás de Aquino" 19, en AAS, 66 (1974) 673-702: especialmente 692.

${ }^{50}$ Cf. CHALMETA, G., La justicia política en Tomás de Aquino. Una interpretación del bien común, Pamplona 2002. 
sí mismas. Además, tiene muy en cuenta la oración y la meditación puesto que en el conocimiento sobrenatural de Dios se encuentra el comienzo y el final de la vida del hombre. La teología supone la fe. Por tanto, lo que el teólogo hace es profundizar con su propia razón humana los misterios de la Revelación Divina. Entender y razonar a partir del dato que le da la fe. Así cuando nos proponemos estudiar teológicamente a Dios, lo hacemos siempre desde lo que Dios mismo nos ha revelado.

En primer lugar, san Agustín pasó a lo largo de su vida por distintos estadios y combatió las tres grandes polémicas: maniqueísmo, donatismo, pelagianismo. El sustrato de su pensamiento en Platón y el neoplatonismo. Santo Tomás perteneció a una línea determinada como fue la escolástica. De esta manera, elegirá como su propio eje filosófico, la filosofía de Aristóteles.

En segundo lugar, para Agustín es verdad que el alma del individuo, no es todo el hombre, sino su parte superior; que su cuerpo, no es del todo el hombre, sino su parte inferior. Por tanto, la unión de ambas se le conoce como el hombre. Para santo Tomas entre el cuerpo y el alma se produce una unión substancial y no accidental, que tienen una relación natural, porque las dos originan la persona, dotado de pensamiento y razón.

En tercer lugar, para Agustín la fe es el presupuesto de la razón. Mantiene su Creo para comprender, Credo ut intelligam. La vinculación existente entre el cristianismo y la filosofía viene desarrollada, desde sus inicios, por el predominio de la fe sobre la razón. Para santo Tomás, el orden de conocimiento natural procede de la razón humana; el orden sobrenatural procede de la revelación $\mathrm{y}$ de la fe y es un conocimiento no del todo claro.

En cuarto lugar, san Agustín no ve la necesidad de separar ambas formas de conocimiento: fe y razón. Dicho conocimiento de las verdades eternas como la justicia, la bondad, la belleza, da lugar a la función superior de la razón. Su finalidad está en alcanzar la verdad. Para santo Tomás, fe y razón están separadas, aunque compartan una zona convergente como son las verdades comunes.

En quinto lugar, san Agustín seguirá la teoría de la conciliación: fe y razón son instrumentos colaboradores para llegar a la verdad única, la filosofía supeditada a la teología; santo Tomás seguirá más bien, la versión de la distinción formal: razón y fe son órdenes del conocimiento con alguna autonomía y manera distinta al acceso a sus contenidos. La filosofía y la teología se hacen independientes con sus objetivos, métodos y puedan concurrir finalmente. 


\section{BIBLIOGRAFÍA}

\section{Fuentes documentales}

- PEDRO DE ARAGÓN, In secundam secundae Divi Thomae Angelici Commentaria. De Iustitia et Iure, Salmanticae 1590.

- SAN AGUSTÍN, De Civitate Dei: PL 41,13-804.

- SAN AGUSTÍN, Confesiones: PL 32,657-868.

- SAN AGUSTÍN, Contra académicos: PL 32, 903-958.

- SAN AGUSTÍN, De moribus Ecclesiae catholicae: PL 32, 1309-1378.

- SAN AGUSTÍN, De doctrina cristiana: PL 34, 15-122.

- SAN AGUSTÍN, Sermón 27, 4: PL 38,178-182.

- SAN AGUSTÍN, De Trinitate: PL 42, 819-1098.

- SANTO TOMÁS DE AQUINO, Summa Theologica, 6 Vol. Romae 1894.

- SANTO TOMÁS DE AQUINO, Suma de Teología, Ed. Dirigida por los Regentes de Estudios de las Provincias Dominicanas en España, 5 Tomos, Madrid 2009.

- SANTO TOMÁS DE AQUINO, La monarquía, Barcelona 2007.

\section{Magisterio}

- BONIFACIO VIII, Bula Unam Sanctam 1302, en Enchiridion symbolorum, definitionum et declarationum de rebus fidei et morum o El magisterio de la Iglesia. Manual de los símbolos, definiciones y declaraciones de la Iglesia en materia de fe y costumbres, Barcelona 2017, DH 870-875, pp. 379-381.

- GREGORIO VII, Bula Dictatus Papae 1075, en Registrum PL: 148, 407-408.

- PABLO VI, "Carta Lumen Ecclesiae en el VII centenario de la muerte de santo Tomás de Aquino”, en AAS 66 (1974) 673-702. 
- TERTUliAnO, "De Carne Christi V, 4", en F. Oehler, Tertulliani opera omnia, Vol. II, 5, Leipzig 1851-1854. También Tertuliano, "De Carne Christi V, 4", en J.- P. MAHE (ED.), La chair du Christ, T. I: Sources Chrétiennes, Paris 1975.

\section{Fuentes secundarias}

- ARQUILliÈRE, H. X., El agustinismo político. Ensayo sobre la formación de las teorías políticas de la Edad Media, Granada 2005.

- BEUCHOT, M., Introducción a la filosofía de Santo Tomás de Aquino, México 2000.

- ChAlmetA, G., La justicia política en Tomás de Aquino. Una interpretación del bien común, Pamplona 2002.

- ELDERS, L., Sobre el método en santo Tomás de Aquino, Buenos Aires 1992.

- ESTAL, G. del, y ROSADO, J. J., "Equivalencia de Civitas en el De Civitate Dei", en La Ciudad de Dios CLXVII, Estudios sobre la Ciudad de Dios, II, El Escorial 1954, pp. 367-454.

- FERRARA, R., "El ministerio sapiencial de la filosofía y la teología especulativa", en Teología, 31(1978) 5-24.

- FISICHELLA, R., "Oportet philosophari in theologia", I-II, en Gregorianum, 76 (1995) 221-262 y 503-534.

- FORMENT, E., Santo Tomás: su vida, su obra y su época, Madrid 2009.

- GARCÍA LÓPEZ, J., Tomás de Aquino, razón y fe, Madrid 1994.

- GILSON, É., Introducción a la Filosofia de Santo Tomás de Aquino, Pamplona (Navarra) 2009.

- GILSON, É., El espiritu de la filosofía medieval, Madrid 2004.

- LACHANCE, L., Humanismo político, Individuo y Estado en Tomás de Aquino, Pamplona 2001. 
- OCÁRIZ, F, y BLANCO, A., Revelación, Fe y Credibilidad. Curso de teología fundamental, Madrid 1998.

- ORTÚZAR, M., “La filosofía de los preámbulos de la fe”, en Estudios, 72 (1966) 3-22.

- PACIONI, V., "Reflexiones sobre la paz en el libro XIX del De Civitate Dei de san Agustín. Suposiciones antropológicas e implicaciones políticas", en Avgvstinvs LXV (2020) 515-546: 528-530.

- PIEPER, J., Introducción a Tomás de Aquino, Madrid 2005.

- PIEPER, J., Defensa de la filosofia, Barcelona 1976, pp. 139-141.

- ROMERO, J. L., La Edad Media, Madrid 2001.

- SANGUINETI, J. J., La filosofía de la ciencia según Santo Tomás, Pamplona 1977. 